\title{
In Situ Spectroscopic Analysis of the Carbothermal Reduction Process of Iron Oxides during Microwave Irradiation
}

\author{
Jun Fukushima * and Hirotsugu Takizawa \\ Department of Applied Chemistry, Tohoku University, Aoba Aramaki, Sendai, Miyagi 980-8579, Japan; \\ takizawa@aim.che.tohoku.ac.jp \\ * Correspondence: fukushima@aim.che.tohoku.ac.jp; Tel.: +81-22-795-7226
}

Received: 25 December 2017; Accepted: 9 January 2018; Published: 11 January 2018

\begin{abstract}
The effects of microwave plasma induction and reduction on the promotion of the carbothermal reduction of iron oxides $\left(\alpha-\mathrm{Fe}_{2} \mathrm{O}_{3}, \gamma-\mathrm{Fe}_{2} \mathrm{O}_{3}\right.$, and $\left.\mathrm{Fe}_{3} \mathrm{O}_{4}\right)$ are investigated using in situ emission spectroscopy measurements during $2.45 \mathrm{GHz}$ microwave processing, and the plasma discharge (such as $\mathrm{CN}$ and $\mathrm{N}_{2}$ ) is measured during microwave E-field irradiation. It is shown that $\mathrm{CN}$ gas or excited $\mathrm{CN}$ molecules contribute to the iron oxide reduction reactions, as well as to the thermal reduction. On the other hand, no plasma is generated during microwave H-field irradiation, resulting in thermal reduction. Magnetite strongly interacts with the microwave H-field, and the reduction reaction is clearly promoted by microwave $\mathrm{H}$-field irradiation, as well as thermal reduction reaction.
\end{abstract}

Keywords: ironmaking; microwaves; carbothermal reduction; iron oxides; emission spectrum

\section{Introduction}

Electromagnetic waves such as microwaves can supply energy to materials effectively, and are thus, expected to be applicable to novel ironmaking processes [1-6]. In the conventional blast-furnace method, the combustion of coke and high-temperature $\mathrm{CO}$ gas requires the delivery of energy to the sites of the reduction reaction. In this method, sintered iron ore and coke are essential to ensure access to CO gas. This iron ore is walnut-sized, and the carbothermal reduction reaction of iron ore is slow. In contrast, in the microwave steelmaking method, microwaves can replace this extra carbon combustion, because they can supply energy to the iron ore or powder directly $[4,7,8]$. Using the microwave process, the reduction of $\mathrm{CO}_{2}$ emissions is estimated to be $55 \%$. Furthermore, by using microwaves as a heat source, it is possible to rapidly produce a pig iron containing about $13 \%$ carbon at $1380{ }^{\circ} \mathrm{C}$, which is $200-300{ }^{\circ} \mathrm{C}$ lower than the temperature of the current blast furnace manufacturing method. In addition, this low-temperature reaction suppresses the reduction of phosphorus oxides, and the amount of generated slag is reduced. A recent in situ study using time-resolved X-ray powder diffraction synchrotron radiation revealed that the reduction of wustite to iron can be achieved at $770{ }^{\circ} \mathrm{C}$ in a microwave $\mathrm{H}$-field [9], compared with over $1100{ }^{\circ} \mathrm{C}$ in an E-field [10]. In summary, the ironmaking method using carbothermal microwave reduction can reduce the $\mathrm{CO}_{2}$ emissions, reaction temperature, and reaction time.

The effects of microwave irradiation on the ironmaking reaction are not restricted to heating only. However, the non-thermal effects on the reduction process of microwave ironmaking are still unknown. Matsubara et al. [11] confirmed the luminescence of Fe at temperatures greater than $1260{ }^{\circ} \mathrm{C}$ using in situ luminescence spectroscopy during the microwave ironmaking process, suggesting that reduction occurs in this low-temperature range. In addition, they reported in another work [12] that a CO peak was observed at $1400{ }^{\circ} \mathrm{C}$, indicating that even the Boudouard reaction proceeds under microwave irradiation. However, these reports showed no clear evidence of microwave specific 
effects. Meanwhile, another effect of microwaves on the reduction reaction has been pointed out in previous studies that have used transition-metal oxides. In the reduction of $\mathrm{TiO}_{2}$, oxygen plasma was detected by spectroscopy during microwave irradiation at $900 \mathrm{~W}$ for $10 \mathrm{~min}$ at the maximum intensity of the microwave electric field in a $10^{-1} \mathrm{~Pa}$ vacuum, and the weak reduction of $\mathrm{TiO}_{2}$ was confirmed [13]. Other papers have reported the reduction of various transition-metal oxides by plasma [14-16]. Sabat et al. [15] mentioned that, typically, the activation energy of plasma-assisted reactions is lower than that of the corresponding standalone reactions. Moreover, the reduction of copper oxide $(\mathrm{CuO})$ occurred during microwave irradiation, and the reduction behavior was different between irradiation by the microwave electric field and the magnetic field [17]. These studies suggest that the effects of plasma and microwave electric and magnetic fields itself can contribute to ironmaking reactions, and these effects result in low-temperature reactions and a shortening of the period of the carbothermal reduction reaction.

In this investigation, to clarify the effects-other than heating-of microwave irradiation, the behavior of the carbothermal reduction reaction was investigated. In particular, in order to verify the reduction effect of plasma arising from an electric field concentration, we used an experimental device capable of in situ visible image acquisition and emission spectroscopy during microwave irradiation.

\section{Materials and Methods}

In this study, we observed the plasma spectrum arising from a mixture of iron oxides and carbon during microwave irradiation. Hematite $(99.9 \%$ purity, $0.3 \mu \mathrm{m}$, Kojundo Chemical Laboratory Co., Ltd., Saitama, Japan), maghemite (99\% purity, 20-40 nm, Kojundo Chemical Laboratory Co., Ltd., Saitama, Japan), and magnetite (99.9\% purity, $<1 \mu \mathrm{m}$, Kojundo Chemical Laboratory Co., Ltd., Saitama, Japan) were used as iron oxides. Each powder was mixed with pure carbon $(99.9 \%$ purity, $50 \mu \mathrm{m}$, Kojundo Chemical Laboratory Co., Ltd., Saitama, Japan), and $0.15 \mathrm{~g}$ of the mixture was compacted to a 6-mm diameter pellet. The molar retio between iron oxides and carbon was 2:3 when hematite and maghemite was used, and 1:2 when magnetite was used. Figure 1 shows a schematic view of the experimental setup.

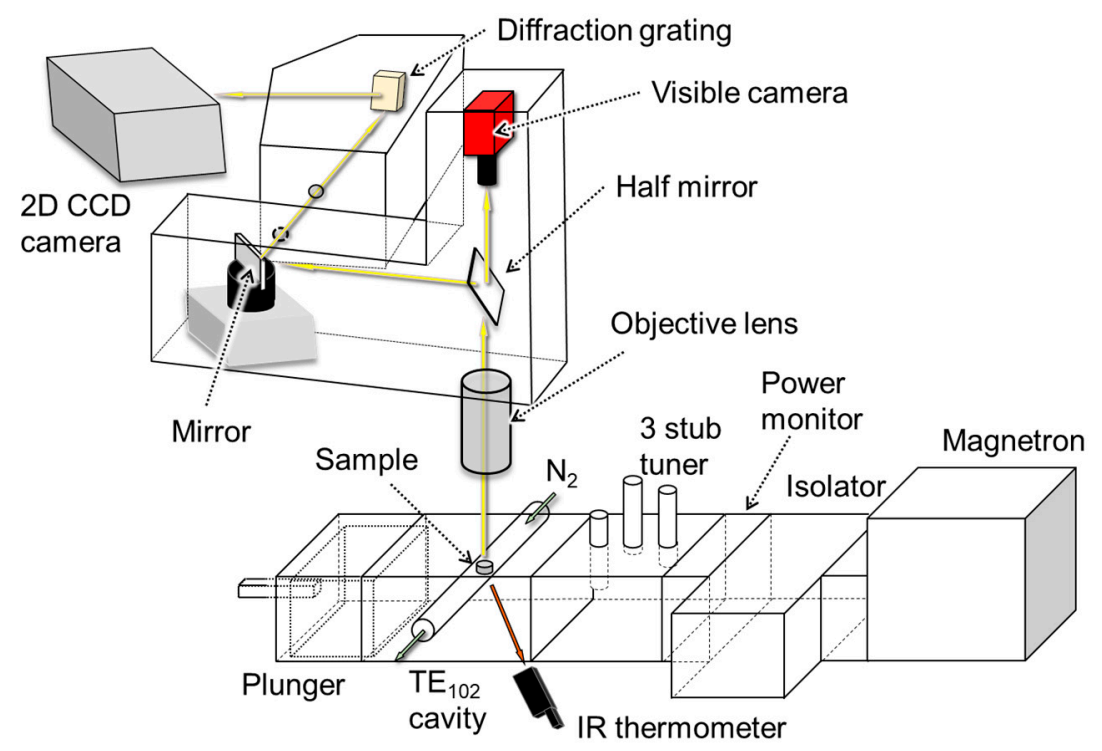

Figure 1. Schematic view of the experimental setup.

The pellet was placed in a quartz test tube, and a flow of $\mathrm{N}_{2}$ gas at $0.1 \mathrm{~L} / \mathrm{min}$ was used. Each pellet was placed at the maximum point of the E-field or H-field microwave intensity in a TE102 single-mode cavity. The sample was irradiated with microwaves by using a magnetron (IMH-20A259, IDX Co., Ltd., Tochigi, Japan, $2455 \pm 15$ MHz). An IR thermometer (FTK9-P300R, Japan Sensor Co., Tokyo, Japan) 
was used to measure the sample temperature from the side of the cavity $(\varepsilon=0.95)$. During microwave irradiation, visible images and emission spectra were obtained by using an integrated microscopic imaging spectrometer (IMIS, Bunkoukeiki Co., Ltd., Tokyo, Japan) [12]. These images and spectra were measured on the upside of the pellet. The spectrometric wavelength ranged from $308 \mathrm{~nm}$ to $492 \mathrm{~nm}$, where the CN line spectra can be observed [18,19]. The measurement conditions of the emission spectra and photograph are listed in Table 1. Line spectra were assigned based on the literature [20-23]. After microwave irradiation, the pellet was ground, and the phases were analyzed by XRD.

Table 1. Measurement conditions of the emission spectra and photograph.

\begin{tabular}{ccc}
\hline & Spectrometer & Visible Camera \\
\hline Exposure time & $0.5 \mathrm{~s}$ & $0.5 \mathrm{~s}$ \\
$\begin{array}{c}\text { Spatial resolution } \\
\text { Wavelength } \\
\text { resolution }\end{array}$ & $4.9 \mu \mathrm{m}^{2}$ & $25 \mu \mathrm{m}^{2}$ \\
\hline
\end{tabular}

\section{Results and Discussions}

\subsection{Spectroscopic Measurements during Microwave Irradiation}

Figure 2 shows the temperature and microwave power profiles of the hematite and carbon mixture irradiated with an E-field (a) and an H-field (b).

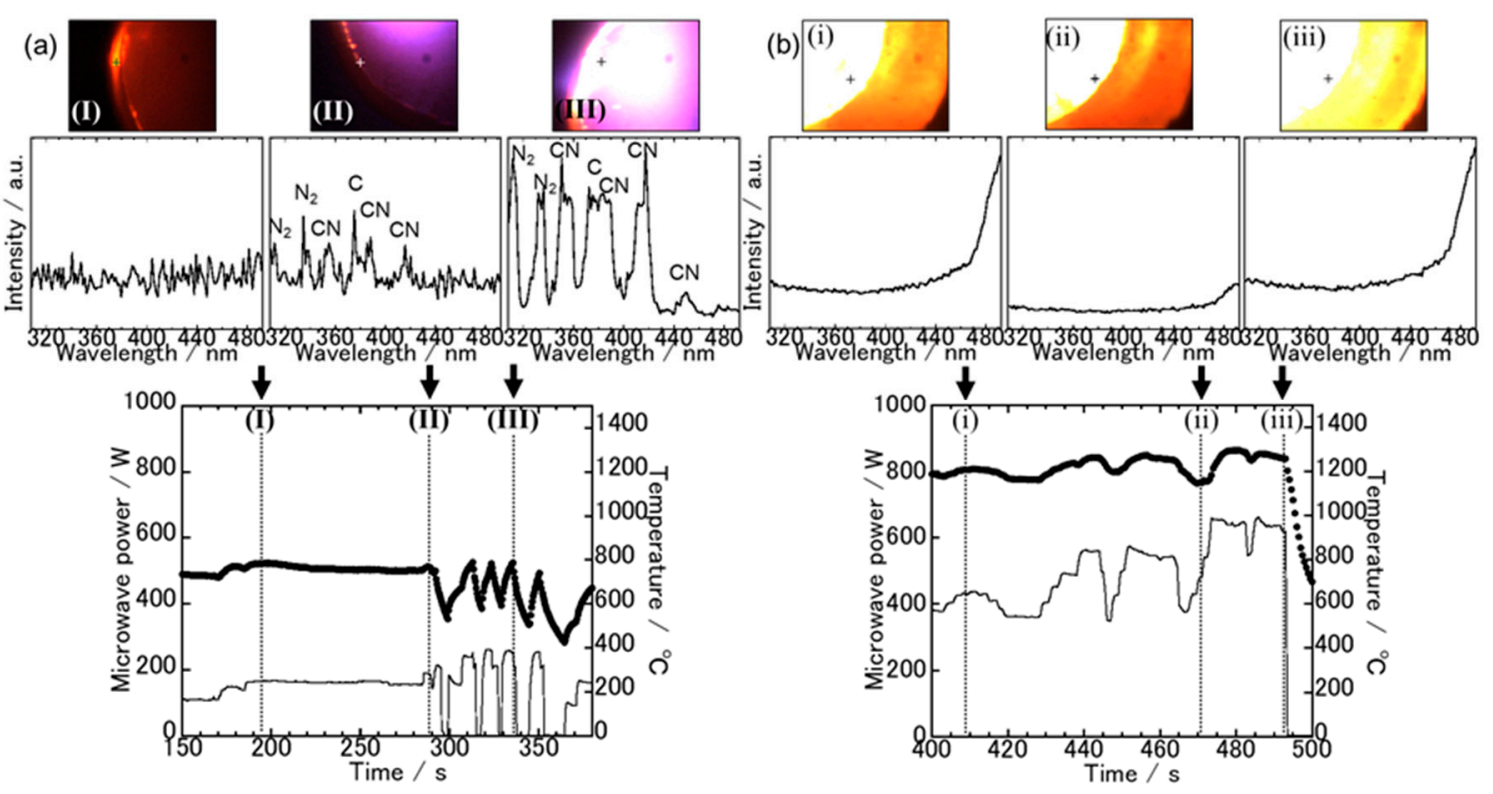

Figure 2. Temperature and microwave power profiles of the hematite and carbon mixture irradiated with an E-field (a) and an H-field (b).

In addition, the visible images and spectra at each time interval, which are indicated by broken lines in each temperature profile, are shown. The spectroscopic measurement points are indicated by cross marks in each visible image. During E-field irradiation, only part of the pellet was heated to a high temperature, and the maximum temperature was about $800{ }^{\circ} \mathrm{C}$ in the measurement area. On the other hand, high-temperature spots can be seen in photo (I). The spectroscopic spectrum of (I) was almost flat between 308-492 nm. However, the temperature of the bright spot was not high, because a continuous spectrum of Planck radiation was not observed in the higher wavelength range. From the spectroscopic result at point (II), weak line spectra corresponding to $\mathrm{CN}, \mathrm{N}_{2}$, and C were observed. However, as shown in the photograph of point (II), purple plasma was generated outside 
of the acquisition area of the visible image; thus, it is considered that the plasma did not affect the reduction reaction of the entire pellet. From the visible image and spectra at point (III), white-purple plasma was generated, which consisted of $\mathrm{CN}, \mathrm{N}_{2}$, and $\mathrm{C}$. This plasma was concentrated only in the upper left part of the pellet. From the above results, although the area of plasma was limited to the upper left part of the pellet, it suggests that the excited molecules of $\mathrm{CN}$ and $\mathrm{N}_{2}$ had some influence on the reduction reaction, in addition to the carbothermal reduction in the E-field processing of hematite.

To examine the relationship between the microwave power, sample temperature, and plasma discharge, the microwave power was increased and decreased several times between 300-350 s. This plasma was discharged when the microwave power reached about $250 \mathrm{~W}$, and the temperature was over $800{ }^{\circ} \mathrm{C}$. In the hematite and carbon system, the microwave E-fields only coupled with carbon, which absorbs the energy. In addition, carbon is a conductive material, and electric fields concentrated between the particles of carbon powder, leading to field electron emission from the carbon. Thus, sufficient electrons for plasma discharge were emitted by thermionic emission at around $800{ }^{\circ} \mathrm{C}$, and by field electron emission over the electric fields of the $250 \mathrm{~W}$ microwaves.

In the $\mathrm{H}$-field processing of the hematite-carbon mixture, as shown in the visible image of Figure $2 b$, the temperature of the whole pellet was increased, and became higher than that in the E-field. From the spectroscopic spectrum at (I), a continuous Planck radiation spectrum appeared in the high-wavelength range, confirming that the sample temperature was higher than that in the E-field. The temperature profiles and spectra at (II) and (III) indicated that the pellet temperature was related to the intensity of the continuous spectra. On the other hand, no line spectra were observed, indicating that excited molecules, such as $\mathrm{CN}^{*}$, were not generated. Therefore, in the $\mathrm{H}$-field processing of the hematite-carbon system, the reduction reaction was dominant in the carbothermal reduction process.

The results for the maghemite-carbon case are shown in Figure 3.

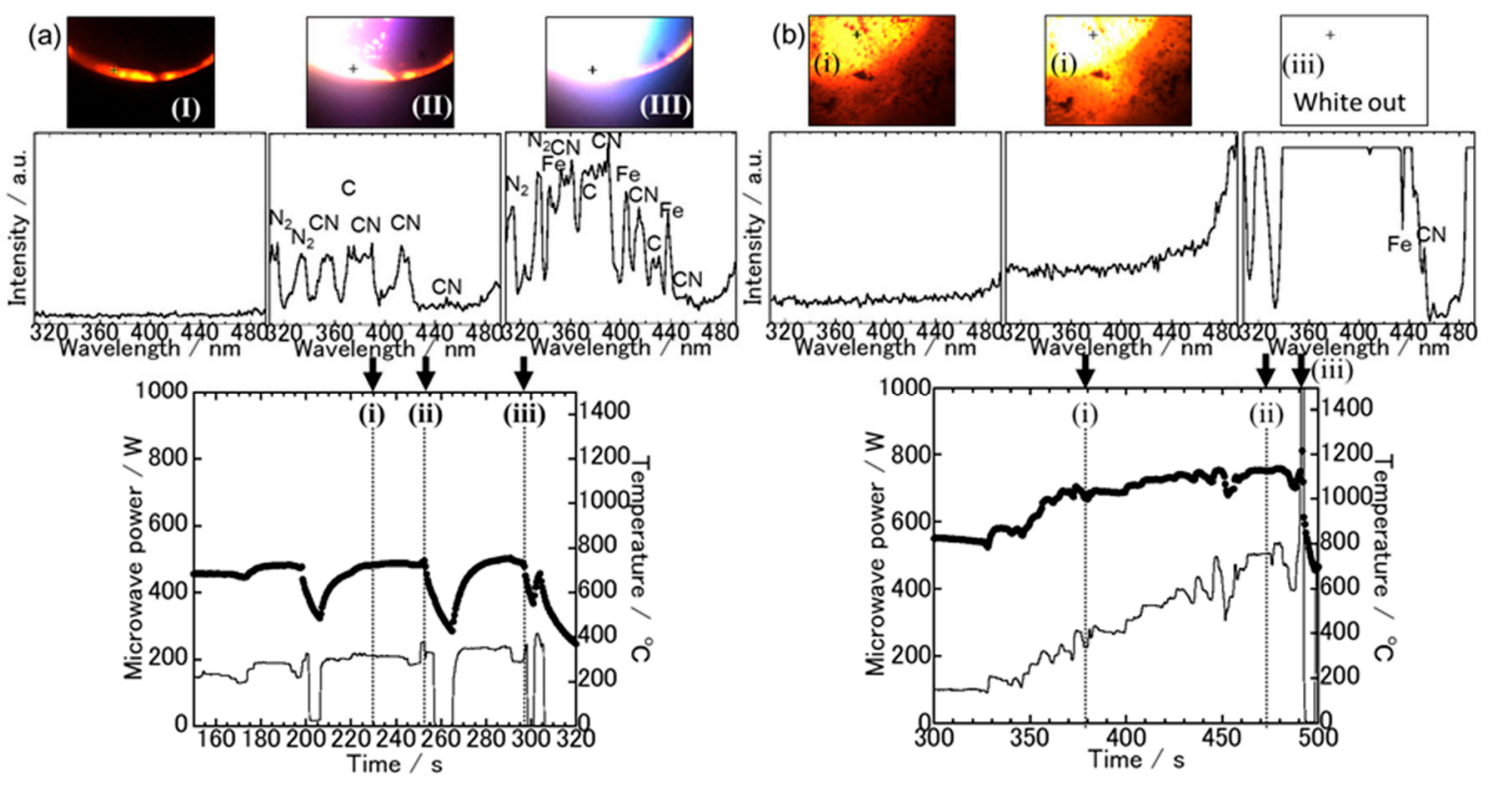

Figure 3. Temperature and microwave power profiles of maghemite and carbon mixture irradiated with an E-field (a) and an H-field (b). The visible images and spectroscopic spectra at each time, which are indicated by broken lines in each temperature profile, are shown.

Just as in the hematite case, in an E-field irradiation, spot heating occurred in the peripheral edge of the pellet, as shown in Figure 3a (I). The spectra at the hot spot were almost flat in the range from $308 \mathrm{~nm}$ to $492 \mathrm{~nm}$, indicating that the spot temperature was not high. In the visible image at point (II), it can be seen that white-purple plasma appeared in the lower left part of the pellet. In addition, relatively strong line spectra were observed at the same time for $\mathrm{CN}, \mathrm{N}_{2}$, and $\mathrm{C}$. At point (III), white blue 
plasma was generated in the same area as (II). The intensity of the line spectra was stronger than that at (II) as a whole, and the line spectra of Fe appeared in addition to $\mathrm{CN}, \mathrm{N}_{2}$, and $\mathrm{C}$. This plasma was discharged when the microwave power exceeded $250 \mathrm{~W}$, and the sample temperature measured by an IR thermometer exceeded $700{ }^{\circ} \mathrm{C}$. Therefore, as with the hematite case, excited molecules such as $\mathrm{CN}^{*}$ had some influence on the reduction reaction, as well as on the carbon thermal reduction reaction. Furthermore, because the line spectra of Fe were observed, the reduction of the surface of the pellet was estimated to have proceeded to a greater degree than in the hematite case.

The sample temperature increased upon irradiation in a magnetic field compared with irradiation in the electric field. From the visible image at point (I), it was found that the temperature of the pellet increased overall. A continuous spectrum was observed on the higher wavelength side, and it was confirmed that the sample temperature was higher than that when heating in an electric field. From the temperature and spectrum of point (II), it was found that the temperature was higher than that of point (III), and the pellet temperature and spectrum shape were related. In addition, from the respective spectral shapes, no emission line spectra were observed; thus, excited molecules of $\mathrm{CN}$, $\mathrm{N}_{2}$, etc., were not present. However, when the microwave power was increased to $600 \mathrm{~W}$, the visible image was a whiteout, and the spectra were partially saturated. We found that when high-intensity microwaves were used, plasma was generated, even in a magnetic field. The spectral saturation was not confirmed between $460-480 \mathrm{~nm}$, but it is inferred that the continuous spectrum is superimposed, and the sample temperature was high. Thus, in irradiation in a magnetic field, the reduction reaction is dominated by the carbothermal reduction process, but the plasma can be excited by increasing the microwave power intensity.

The results of the magnetite case are shown in Figure 4.
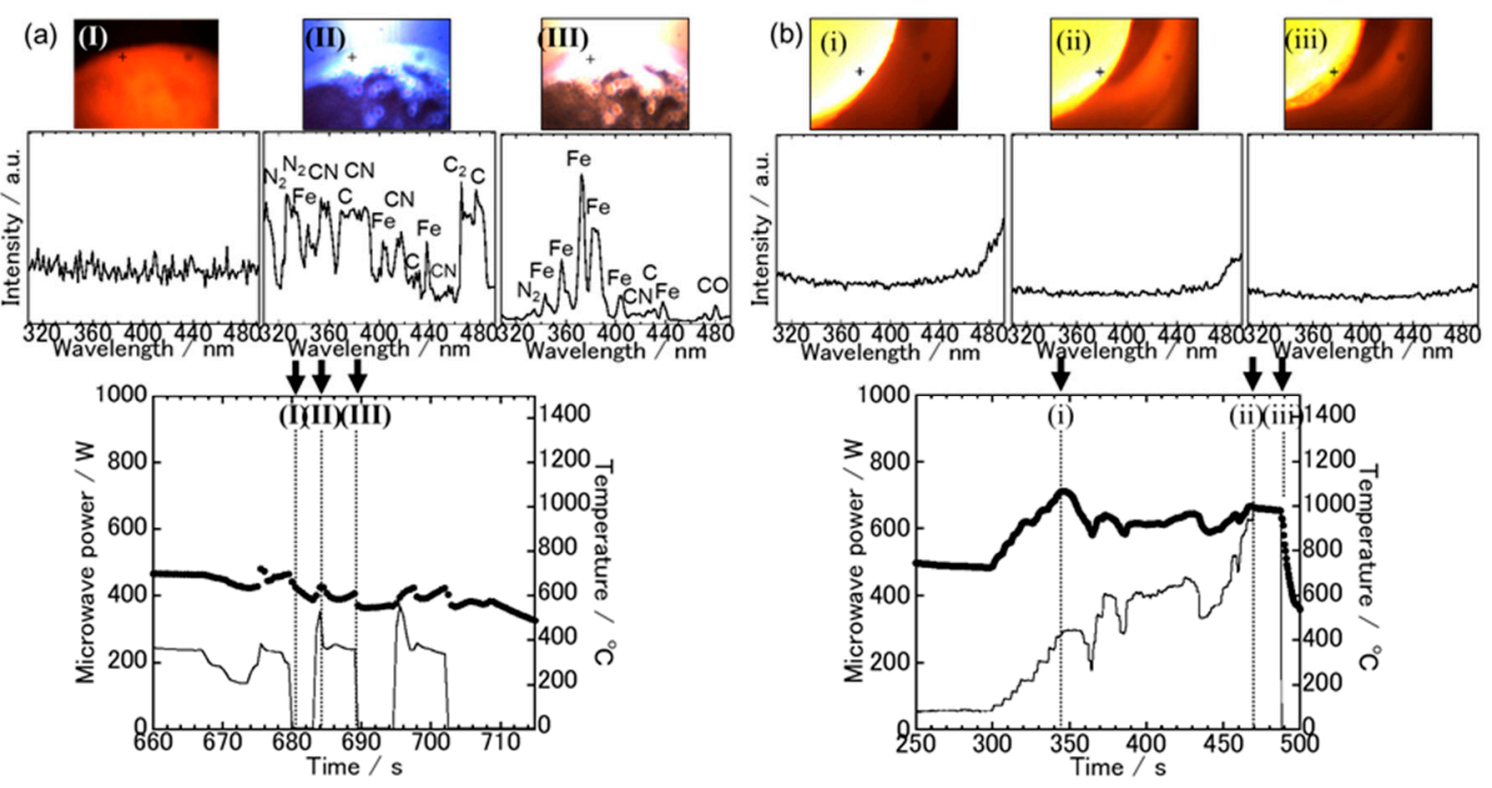

Figure 4. Temperature and microwave power profiles of the magnetite and carbon mixture irradiated with an E-field (a) and an H-field (b). The visible images and spectroscopic spectra at each time, which are indicated by broken lines in each temperature profile, are shown.

In an E-field irradiation, unlike the other case, the temperature of the sample increased relatively uniformly, as shown in the visible image of point (I). The spectrum at that point was almost linear in the range of $308 \mathrm{~nm}$ to $492 \mathrm{~nm}$. Accordingly, the temperature at the cross point was under $1100{ }^{\circ} \mathrm{C}$. At point (II), white-blue plasma was generated in the upper part of the pellet, and spectra corresponding to $\mathrm{CN}, \mathrm{N}_{2}, \mathrm{C}$, and Fe were observed in the spectroscopic results at that time. On the other hand, at point (III), white-orange plasma was generated. This plasma consisted of mainly strong 
line spectra of Fe and $\mathrm{CO}, \mathrm{N}_{2}, \mathrm{CN}$, and C plasma. This transition of the plasma color occurred from $685 \mathrm{~s}$ to $690 \mathrm{~s}$, and the intensity of the Fe line spectra increased with increasing time. This result suggests that the reduction reaction proceeded. This plasma was ignited at microwave powers greater than $250 \mathrm{~W}$ and temperatures greater than $600{ }^{\circ} \mathrm{C}$ in the area of IR measurement, and the area was confined to the upper part of the pellet. Therefore, this result suggests that the plasma induced the reduction reaction, resulting in an increase in the intensity of the Fe line spectra with increasing plasma exposure time.

In H-field irradiation with the magnetite-carbon mixture, the sample temperature became higher than that irradiated by the electric field, but the temperature was lower than that in the cases of hematite and maghemite. From the visible image at point (I), it was observed that the temperature in the peripheral edge of the pellet was higher than that in the center of the pellet. In the spectrum, continuous spectra were observed on the high wavelength side, and the sample temperature was confirmed to be higher than that in an E-field. The intensity of the continuous spectrum was weaker than that of hematite and maghemite, which is consistent with the temperature profiles. However, after $350 \mathrm{~s}$, the heating behaviour of the sample changed, and significant power was required to increase the sample temperature. From the temperature and spectra of points (II) and (III), the change of the sample temperature corresponded to the intensity of the spectra. In any case, line spectra were not observed, suggesting no generation of plasma.

\subsection{The Sample Reduction State after Microwave Irradiation}

From the spectroscopy results and the temperature profiles, it is considered that the reduction behavior differed with the microwave irradiation mode. Therefore, XRD results are shown in each irradiation mode, and not for each iron oxide.

Figure 5 shows the XRD results and photographs of the sample after irradiation with the E-field.

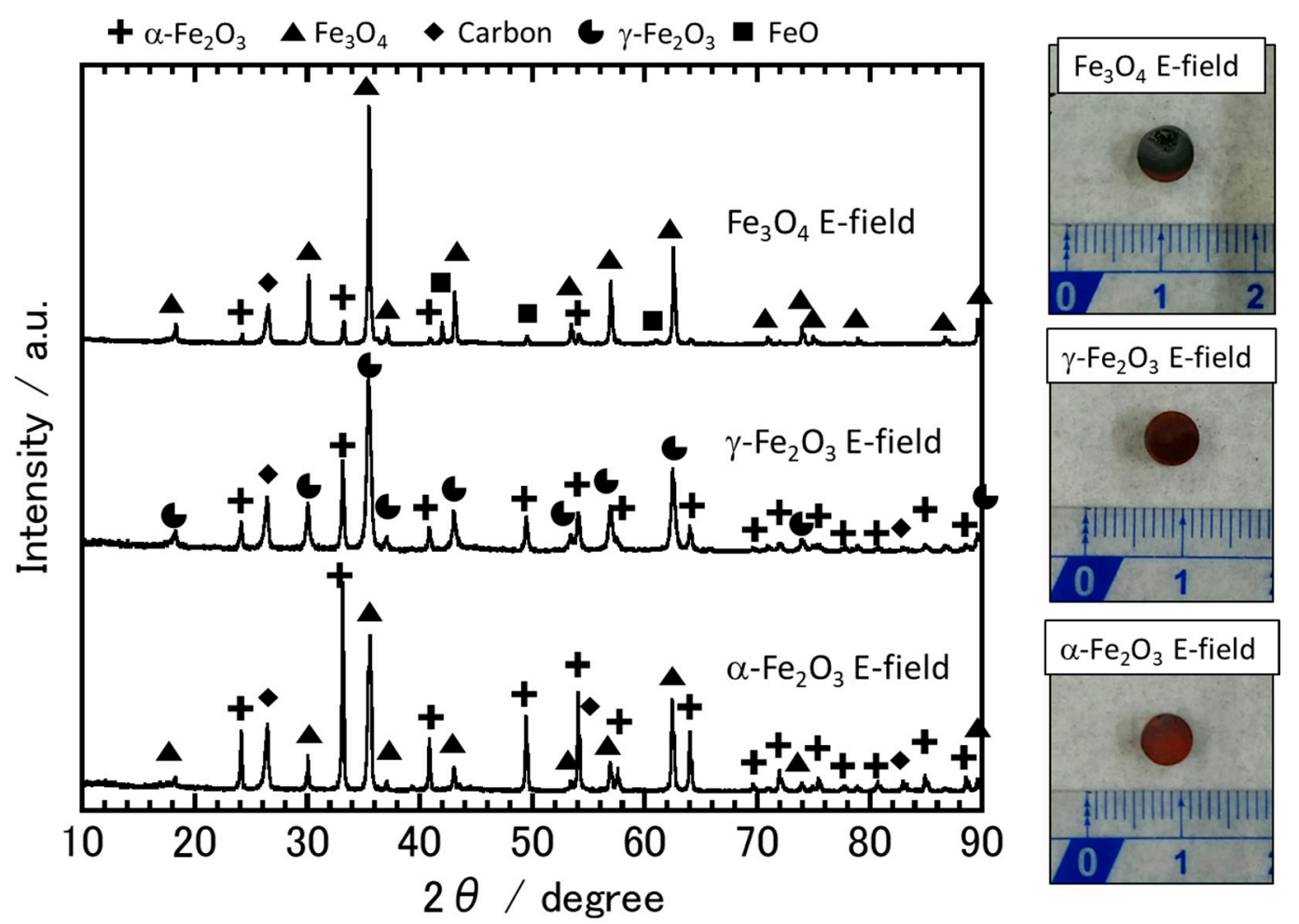

Figure 5. XRD results and photographs of the sample after irradiation with E-fields.

The hematite sample was reddish brown as a whole, and the pristine hematite and carbon remained present, as illustrated by the XRD result. This is because most of the pellet area was as low as 
$800^{\circ} \mathrm{C}$. On the other hand, as can be inferred from the visible image and the spectroscopic results shown in Figure 2a, the color of the upper left part of the pellet was partially discolored and turned black. A small amount of magnetite was observed in the XRD pattern, suggesting that the reduction reaction was driven by the thermal energy of the plasma or by excited $\mathrm{C}$ and $\mathrm{CN}$ molecules. The reduction of hematite with carbon or CN gas to produce magnetite can be represented by Equations (1) and (2).

$$
\begin{gathered}
6 \mathrm{Fe}_{2} \mathrm{O}_{3}+\mathrm{C} \rightarrow 4 \mathrm{Fe}_{3} \mathrm{O}_{4}+\mathrm{CO}_{2} \\
6 \mathrm{Fe}_{2} \mathrm{O}_{3}+\mathrm{CN} \rightarrow 4 \mathrm{Fe}_{3} \mathrm{O}_{4}+\mathrm{CO}_{2}+\mathrm{N}_{2}
\end{gathered}
$$

At $927^{\circ} \mathrm{C}$, the $\Delta \mathrm{Go}$ of Equations (1) and (2) are -144.24 and $-152.66 \mathrm{~kJ} / \mathrm{mol}$, respectively [24]. In addition, it is considered that excited $\mathrm{CN}$ molecules can transfer their energy to other molecules or atoms, and the energy can be used for the reduction reaction. Therefore, the reduction reaction of hematite with CN gas would proceed easily.

The XRD results of maghemite indicated that the pristine sample remained and was partly oxidized to hematite. However, from the spectroscopic results of maghemite, as shown in Figure 3a at point (III), it is inferred that the sample was reduced. This is because it was hard to distinguish between trace amounts of magnetite and maghemite from the XRD results. In addition, because the area of plasma was limited to the lower left part of the pellet, maghemite was oxidized to hematite in the other areas.

The XRD results for magnetite illustrate that the sample remained unchanged: partially oxidized to hematite and partly reduced to wustite. From the photograph, the upper part of the pellet is discolored and gray. The lower part is reddish brown. The upper part corresponds to the area of the plasma discharge, having been reduced and converted to wustite. Conversely, the lower part became reddish brown, and it was thought to be oxidized. When plasma is discharged, microwaves tend to be absorbed or reflected by the plasma, resulting in a temperature decrease at the outside of the discharged area of the plasma. Therefore, in the lower part of the pellet, where plasma was not discharged, the sample temperature became relatively low, and oxidation proceeded.

Figure 6 shows the XRD results and photographs of the sample after irradiation with H-fields.

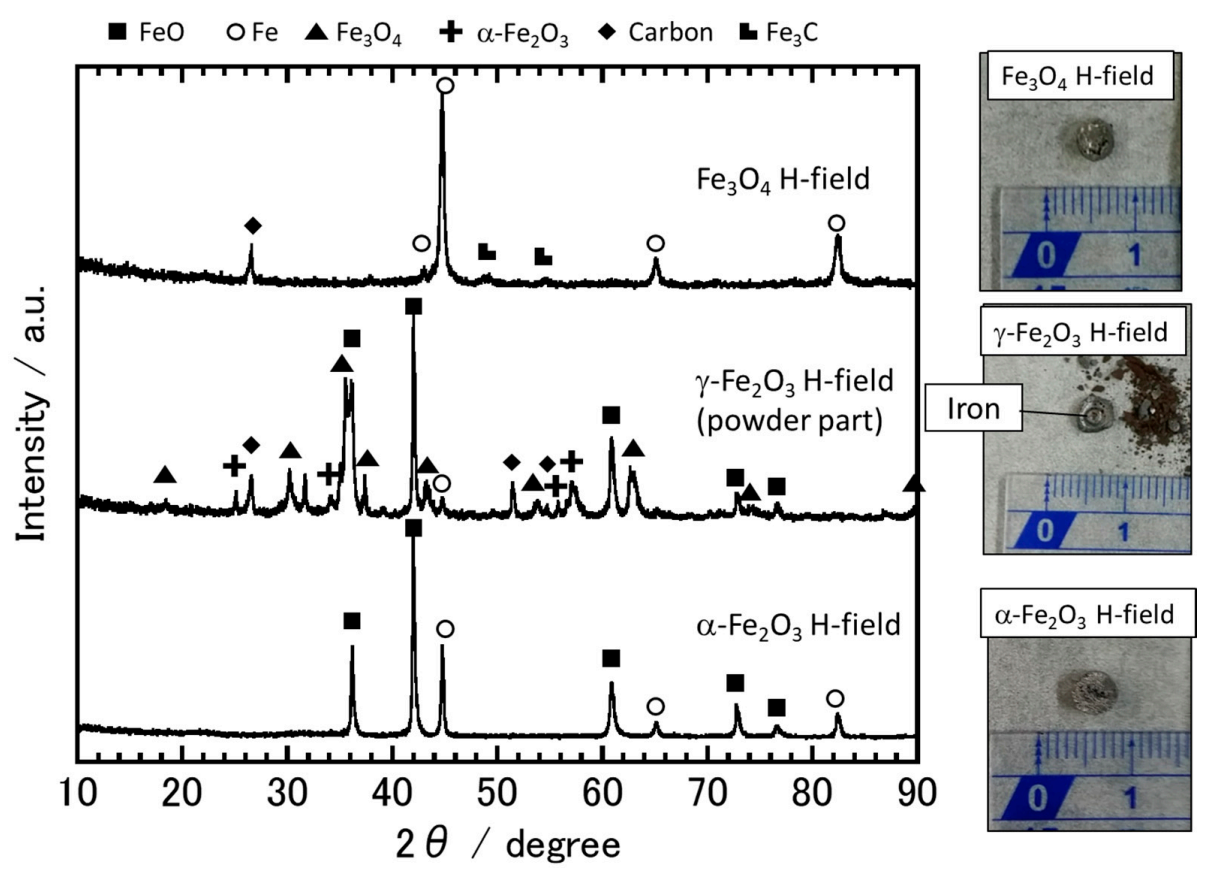

Figure 6. XRD results and photographs of the sample after irradiation with $\mathrm{H}$-fields. 
Hematite was reduced by irradiation with $\mathrm{H}$-fields, leading to the formation of wustite and an iron phase. Residual carbon was not observed, despite the incomplete reduction reaction. On the other hand, from the XRD results for magnetite, it was observed that carbon remained, even though the magnetite had been completely reduced to iron. The reason is that when the hematite was irradiated with an $\mathrm{H}$-field, the reaction temperature was relatively high: over $120{ }^{\circ} \mathrm{C}$. Ishizaki et al. reported that when the temperature is about $1000{ }^{\circ} \mathrm{C}, \mathrm{CO}$ gas is produced from $\mathrm{CO}_{2}$ by the Boudouard reaction [25]. Thus, in the $\mathrm{H}$-field processing of hematite, the reaction between solid carbon and $\mathrm{CO}_{2}$ gas proceeded well by the Boudouard reaction, and all of the solid carbon was consumed.

As shown in the photograph, the maghemite pellet was partially crushed during the heating process, and the crushed part was analyzed by XRD. The crushed powder contained hematite, magnetite, carbon, wustite, and iron. On the other hand, the pellet part was iron, suggesting that the reduction reaction proceeded sufficiently.

From the XRD results for magnetite, almost all of the sample was reduced to iron, although some residual carbon and a trace amount of $\mathrm{Fe}_{3} \mathrm{C}$ was observed. In contrast to the hematite case, residual carbon was observed in the sample after irradiation, even though all of the magnetite had been completely reduced to iron. The results suggest that magnetite was reduced by the special effect of the microwave H-fields, as well as by the carbothermal reduction. Previous reports have shown that the reduction reactions of some transition-metal oxides, such as $\mathrm{CuO}$ and $\mathrm{TiO}_{2}$, are promoted by microwave irradiation $[17,26,27]$. In particular, the reduction reaction of $\mathrm{NiMn}_{2} \mathrm{O}_{4}$, which has a similar crystal structure to magnetite, is promoted by microwave $\mathrm{H}$-field irradiation, and the author emphasized that the promotion effect was derived from the interaction between the spins of the sample and the microwave H-field. Other papers have shown that the interaction between the spins and $\mathrm{H}$-fields remain above the Curie temperature [28]. Therefore, it is suggested that microwave H-fields promoted the reduction of magnetite at temperatures greater than $1000^{\circ} \mathrm{C}$.

\section{Conclusions}

In situ emission spectroscopy during microwave processing was conducted using $2.45 \mathrm{GHz}$ single-mode microwave irradiation furnace. Plasma discharge was observed during microwave E-field irradiation using the in situ spectroscopic measurement device. We believe that $\mathrm{CN}$ gas or excited $\mathrm{CN}$ molecules contributed to the reduction reaction of iron oxides, in addition to thermal reduction. On the other hand, no excited molecules were generated during microwave $\mathrm{H}$-field irradiation. Thus, thermal reduction mainly occurred. Magnetite strongly interacts with the microwave $\mathrm{H}$-field, suggesting that the reduction reaction of magnetite was promoted by microwave H-field irradiation, as well as by the thermal reduction reaction. We believe that the energy consumption for the formation of iron by microwave processing would be decreased by controlling the plasma discharge by changing the powder particle size, mixed state, and microwave irradiation condition.

Acknowledgments: This work was supported by a JSPS Grant-in-Aid for Scientific Research (S) No. JP17H06156. Author Contributions: J.F. and H.T. conceived and designed the experiments; J.F. performed the experiments; J.F. analyzed the data; H.T. contributed reagents/materials/analysis tools; J.F. wrote the paper.

Conflicts of Interest: The authors declare no conflict of interest.

\section{References}

1. Ishizaki, K.; Nagata, K.; Hayashi, T. Localized Heating and Reduction of Magnetite Ore with Coal in Composite Pellets Using Microwave Irradiation. ISIJ Int. 2007, 47, 817-822. [CrossRef]

2. Kashimura, K.; Sato, M.; Hotta, M.; Agrawal, D.K.; Nagata, K.; Hayashi, M.; Mitani, T.; Shinohara, N. Iron production from $\mathrm{Fe}_{3} \mathrm{O}_{4}$ and graphite by applying $915 \mathrm{MHz}$ microwaves. Mater. Sci. Eng. A 2012, 556, 977-979. [CrossRef]

3. Castro, E.R.D.; Moura, M.B.; Jermolovicius, Ã.L.A.; Takano, C. Carbothermal reduction of iron ore applying microwave energy. Steel Res. Int. 2012, 83, 131-138. [CrossRef] 
4. Hara, K.; Hayashi, M.; Sato, M.; Nagata, K. Continuous Pig Iron Making by Microwave. J. Microw. Power Electromagn. Energy 2011, 45, 137-147. [CrossRef] [PubMed]

5. Hara, K.; Hayashi, M.; Sato, M.; Nagata, K. Pig Iron Making by Focused Microwave Beams with 20 kW at 2.45 GHz. ISIJ Int. 2012, 52, 2149-2157. [CrossRef]

6. Sabelström, N.; Hayashi, M.; Yokoyama, Y.; Watanabe, T.; Nagata, K. XRD In Situ Observation of Carbothermic Reduction of Magnetite Powder in Microwave Electric and Magnetic Fields. Steel Res. Int. 2013, 84, 975-981. [CrossRef]

7. Nagata, K.; Sato, M.; Hara, K.; Hotta, T.; Kitamura, Y.; Hayashi, M.; Kashimura, K.; Mitani, T.; Fukushima, J. Microwave Blast Furnace and Its Refractories. J. Tech. Assoc. Refract. Jpn. 2014, 34, 66-73.

8. Kashimura, K.; Nagata, K.; Sato, M. Concept of Furnace for Metal Refining by Microwave Heating-A Design of Microwave Smelting Furnace with Low $\mathrm{CO}_{2}$ Emission. Mater. Trans. 2010, 51, 1847-1853. [CrossRef]

9. Ishizaki, K.; Stir, M.; Gozzo, F.; Catalá-Civera, J.M.; Vaucher, S.; Nicula, R. Magnetic microwave heating of magnetite-carbon black mixtures. Mater. Chem. Phys. 2012, 134, 1007-1012. [CrossRef]

10. Stir, M.; Ishizaki, K.; Vaucher, S.; Nicula, R. Mechanism and kinetics of the reduction of magnetite to iron during heating in a microwave E-field maximum. J. Appl. Phys. 2009, 105, 124901. [CrossRef]

11. Matsubara, A.; Takayama, S.; Okajima, S.; Sato, M. Evolution of the Near-UV Emission Spectrum Associated with the Reduction Process in Microwave Iron Making. J. Microw. Power Electromagn. Energy 2008, 42, 4-8. [CrossRef] [PubMed]

12. Matsubara, A.; Nakayama, K.; Okajima, S.; Sato, M. Microscopic and Spectroscopic Observations of Plasma Generation in the Microwave Heating of Powder Material. Plasma Fusion Res. 2010, 5, 041. [CrossRef]

13. Sonobe, T.; Mitani, T.; Shinohara, N.; Hachiya, K.; Yoshikawa, S. Plasma emission and surface reduction of titanium dioxides by microwave irradiation. Jpn. J. Appl. Phys. 2009, 48, 116003. [CrossRef]

14. Sabat, K.C.; Paramguru, R.K.; Mishra, B.K. Reduction of Oxide Mixtures of $\left(\mathrm{Fe}_{2} \mathrm{O}_{3}+\mathrm{CuO}\right)$ and $\left(\mathrm{Fe}_{2} \mathrm{O}_{3}+\mathrm{Co}_{3} \mathrm{O}_{4}\right)$ by Low-Temperature Hydrogen Plasma. Plasma Chem. Plasma Process. 2017, 37, 979-995. [CrossRef]

15. Sabat, K.C.; Rajput, P.; Paramguru, R.K.; Bhoi, B.; Mishra, B.K. Reduction of Oxide Minerals by Hydrogen Plasma: An Overview. Plasma Chem. Plasma Process. 2014, 34, 1-23. [CrossRef]

16. Kitamura, T.; Shibata, K.; Takeda, K. In-fright Reduction of $\mathrm{Fe}_{2} \mathrm{O}_{3}, \mathrm{Cr}_{2} \mathrm{O}_{3}, \mathrm{TiO}_{2}$ and $\mathrm{Al}_{2} \mathrm{O}_{3}$ by $\mathrm{Ar}-\mathrm{H}_{2}$ and Ar- $\mathrm{CH}_{4}$ Plasma. ISIJ Int. 1993, 33, 1150-1158. [CrossRef]

17. Fukushima, J.; Kashimura, K.; Takayama, S.; Sato, M.; Sano, S.; Hayashi, Y.; Takizawa, H. In-situ kinetic study on non-thermal reduction reaction of $\mathrm{CuO}$ during microwave heating. Mater. Lett. 2013, 91, $252-254$. [CrossRef]

18. Dong, M.; Lu, J.; Yao, S.; Zhong, Z.; Li, J.; Li, J.; Lu, W. Experimental study on the characteristics of molecular emission spectroscopy for the analysis of solid materials containing C and N. Opt. Express 2011, 19, 17021-17029. [CrossRef] [PubMed]

19. Wasowicz, T.J.; Kivimäki, A.; Coreno, M.; Zubek, M. Superexcited states in the vacuum-ultraviolet photofragmentation of isoxazole molecules. J. Phys. B Atom. Mol. Opt. Phys. 2012, 45, 205103. [CrossRef]

20. Pearse, R.W.B.; Gaydon, A.G. The Identification of Molecular Spectra, 3rd ed.; Chapman and Hall: London, UK, 1965.

21. Voevodin, A.A.; Jones, J.G.; Zabinski, J.S.; Hultman, L. Plasma characterization during laser ablation of graphite in nitrogen for the growth of fullerene-like $\mathrm{CN}_{x}$ films. J. Appl. Phys. 2002, 92, 724-735. [CrossRef]

22. Bourquard, F.; Maddi, C.; Donnet, C.; Loir, A.-S.; Barnier, V.; Wolski, K.; Garrelie, F. Effect of nitrogen surrounding gas and plasma assistance on nitrogen incorporation in a-C:N films by femtosecond pulsed laser deposition. Appl. Surf. Sci. 2016, 374, 104-111. [CrossRef]

23. Kraus, M.; Egli, W.; Haffner, K.; Eliasson, B.; Kogelschatz, U.; Wokaun, A. Investigation of mechanistic aspects of the catalytic $\mathrm{CO}_{2}$ reforming of methane in a dielectric-barrier discharge using optical emission. Phys. Chem. Chem. Phys. 2002, 4, 668-675. [CrossRef]

24. Chase, M.W.J. (Ed.) NIST-JANAF Thermochemical Tables, 4th ed.; American Institute of Physics: College Park, MD, USA, 1998.

25. Ishizaki, K.; Nagata, K. Microwave Induced Solid-Solid Reactions between $\mathrm{Fe}_{3} \mathrm{O}_{4}$ and Carbon Black Powders. ISIJ Int. 2008, 48, 1159-1164. [CrossRef]

26. Fukushima, J.; Kashimura, K.; Sato, M. Chemical bond cleavage induced by electron heating Gas emission behavior of titanium-metalloid compounds (titanium nitride and oxide) in a microwave field. Mater. Chem. Phys. 2011, 131, 178-183. [CrossRef] 
27. Fukushima, J.; Kashimura, K.; Takayama, S.; Sato, M. Microwave-energy Distribution for Reduction and Decrystallization of Titanium Oxides. Chem. Lett. 2012, 41, 39-41. [CrossRef]

28. Tanaka, M.; Kono, H.; Maruyama, K. Selective heating mechanism of magnetic metal oxides by a microwave magnetic field. Phys. Rev. B 2009, 79, 104420. [CrossRef] 